\title{
Development of a light-regulated cell-recovery system for non-photosynthetic bacteria
}

\author{
Mitsuharu Nakajima ${ }^{1,2}, K$ Koichi Abe ${ }^{1,2}$, Stefano Ferri ${ }^{1,2,3}$ and Koji Sode ${ }^{1,2^{*}}$
}

\begin{abstract}
Background: Recent advances in the understanding of photosensing in biological systems have enabled the use of photoreceptors as novel genetic tools. Exploiting various photoreceptors that cyanobacteria possess, a green lightinducible gene expression system was previously developed for the regulation of gene expression in cyanobacteria. However, the applications of cyanobacterial photoreceptors are not limited to these bacteria but are also available for non-photosynthetic microorganisms by the coexpression of a cyanobacterial chromophore with a cyanobacteriaderived photosensing system. An Escherichia coli-derived self-aggregation system based on Antigen 43 (Ag43) has been shown to induce cell self-aggregation of various bacteria by exogenous introduction of the Ag43 gene.

Results: An E. coli transformant harboring a plasmid encoding the Ag43 structural gene under a green light-regulated gene expression system derived from the cyanobacterium Synechocystis sp. PCC6803 was constructed. Ag43

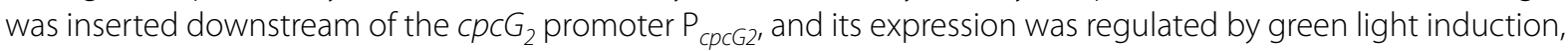
which was achieved by the functional expression of cyanobacterial CcaS/CcaR by coexpressing its chromophore synthesis gene cassette in E. coli. E. coli transformants harboring this designed system self-aggregated under green light exposure and precipitated, whereas transformants lacking the green light induction system did not. The green light induction system effectively functioned before the cell culture entered the stationary growth phase, and approximately $80 \%$ of the cell culture was recovered by simple decantation.
\end{abstract}

Conclusion: This study demonstrated the construction of a cell recovery system for non-photosynthetic microorganisms induced by exposure of cells to green light. The system was regulated by a two-component regulatory system from cyanobacteria, and cell precipitation was mediated by an autotransporter protein, Ag43. Although further strict control and an increase of cell recovery efficiency are necessary, the system represents a novel tool for future bioprocessing with reduced energy and labor required for cell recovery.

Keywords: Antigen 43, Green light induction, Cell recovery, Green light sensor, Optogenetics, Escherichia coli

\section{Background}

Recent advances in the understanding of photosensing in biological systems have permitted the use of photoreceptors as novel genetic tools [1-8]. Photoreceptors are protein machineries that detect and respond to changes in light quality and intensity. Optogenetics, which uses

\footnotetext{
*Correspondence: sode@cc.tuat.ac.jp

${ }^{1}$ Department of Biotechnology and Life Science, Graduate School of Engineering, Tokyo University of Agriculture \& Technology, 2-24-16 Naka-cho, Koganei, Tokyo 184-8588, Japan

Full list of author information is available at the end of the article
}

various photoreceptors to control cell behaviors directly via light exposure, has recently attracted attention as a synthetic biology-based bioprocess design.

Cyanobacteria have various light-sensing systems to effectively regulate photosynthesis $[9,10]$ and avoid photo-inhibition caused by strong or short-wavelength light [11-17]. By exploiting various photoreceptors in cyanobacteria, a green light-inducible gene expression system has been developed. A unicellular cyanobacterium, Synechocystis sp. PCC6803, harbors a green lightsensing system. The expression of a phycobilisome linker 
gene, $c p c G 2$, is chromatically regulated by a sensor histidine kinase, $\mathrm{CcaS}$, and a cognate response regulator, CcaR [18]. Using the endogenous CcaS/CcaR system, the green light regulation of an exogenously induced gene was achieved using a modified promoter of $c p c G 2, \mathrm{P}_{c p c G 2}$, inserted upstream of the target gene on a vector plasmid [19]. In addition, CcaS, CcaR, and $\mathrm{P}_{c p c G 2}$ from Synechocystis sp. PCC6803 has been transformed into the marine cyanobacterium Synechococcus sp. NKBG 15041c as an exogenous green light-regulated gene expression system [20]. This system has been applied to the construction of a green light-regulated autolysis system for cyanobacteria that employs a T4 phage-derived lysis system under the control of green light-regulated gene expression [21].

However, the applications of cyanobacterial photoreceptors are not limited to cyanobacteria but are also available for non-photosynthetic microorganisms. A pioneering study by Tabor et al. achieved the functional expression and utilization of a cyanobacterium-derived green light-sensing system in E. coli [22]. Because phycocyanobilin (PCB), a chromophore of CcaS, is not endogenously synthesized in $E$. coli, the coexpression of a PCB synthesis gene cassette together with $\mathrm{CcaS} / \mathrm{CcaR}$ resulted in green light-regulated gene expression in E. coli [23]. Tabor and his coworkers also reported a multichromatic gene expression system employing an engineered CcaS.

In this study, we aimed to construct a novel technology for non-photosynthetic microorganism-based bioprocesses, a light-regulated cell-recovery system. As a light-regulated gene expression system, the cyanobacterium-derived green light-regulated gene expression system controlled by the two-component regulatory system $\mathrm{CcaS} / \mathrm{CcaR}$ was selected. For the cell recovery technology, the $E$. coli-derived self-aggregation system was selected. Antigen 43 (Ag43), an autotransporter protein from $E$. $\mathrm{coli}$, is an essential protein for aggregation and biofilm formation during infection. Ag43 is composed of three domains: a signal peptide for secretion into the periplasmic space, a $\beta$ domain that forms a selective channel in the outer membrane to transfer the $\alpha$ domain for extracellular display, and an $\alpha$ domain, which is a linker for the self-aggregation. High affinity among the $\alpha$ domains triggers self-aggregation, which leads to cell precipitation [24-28]. Recently, the structure of the $\alpha$-domain complex of Ag43 has been reported [29]. In the present study, the Ag43 structural gene was inserted downstream of the $c p c G_{2}$ promoter, $\mathrm{P}_{c p c G 2}$, and its expression was regulated by green light induction, achieved by the functional expression of cyanobacterial $\mathrm{CcaS} / \mathrm{CcaR}$ by coexpression of its chromophore synthesis gene cassette in E. coli. E. coli transformants carrying this system self-aggregated under green light exposure and precipitated, whereas transformants lacking the green light-induction system did not. The green light-induction system effectively functioned before the cell culture entered the stationary growth phase, and approximately $80 \%$ of the cell culture was recovered by simple decantation.

\section{Methods}

Construction of a plasmid encoding a green light-inducible aggregation system

Gene encoding the aggregation protein, ag43 derived from E. coli amplified from BioBrick BBa_K317008 (Registry of Standard Biological Parts [30]) was inserted downstream of a $\mathrm{P}_{c p c G 2}$ promoter corresponding to the NdeI and XbaI sites of pKTGSS, which contains the green light-sensing two-component regulatory system CcaS/CcaR [20]. The resulting plasmid was designated as pKTGLAg. The gene cassette containing the green light-inducible aggregation system was amplified by PCR using primers 5'-AGCGGCCGCGAATTCTTGAAGACGAAAGGGCCTC-3' and 5'-TTTTTTCGCCTGCAGATGGAAGCCGGCGGCAC-3' and pKTGLAg as a template. The plasmid pBR322 was linearized and the region, except for the TetC-coding gene, was amplified using primers $5^{\prime}$-GAATTCGCGGCCGCTTCTAG-3' and $5^{\prime}$ - CTGCAGGCGAAAAAACCCCGCCGAAG-3' [31]. These amplified products were fused with an InFusion cloning kit (Takara, Otsu, Japan). The constructed vectors comprising the green light-inducible aggregation system (pBRGLAg) are shown in Fig. 1. Control vectors with each component deleted were also constructed by inverse PCR using pBRGLAg with primers designed to eliminate $c c a S$ or $c c a R$ (pBRGLAg $\Delta S$, pBRGLAg $\Delta \mathrm{R}$, and pBRGLAg $\triangle S R$ ). These constructed vectors are shown in Fig. 1, and the components are described in Table 1.

\section{Construction of a plasmid encoding PCB synthesis genes}

A PCB synthesis gene cassette was constructed by assembling $\mathrm{P}_{\text {LtetO-1 }}$ (BBa_R0040; Registry of Standard Biological Parts [30]), a ribosomal binding site (RBS) (BBa_B0034; Registry of Standard Biological Parts [30]), the heme oxygenase gene ho1 from Synechocystis sp. PCC6803 (BBa_ I15008; Registry of Standard Biological Parts [30]), the PCB-thioredoxin oxidoreductase gene $p c y A$ from Synechocystis sp. PCC6803 (BBa_I15009; Registry of Standard Biological Parts [30]), and a double terminator (BBa B0015; Registry of Standard Biological Parts [30]) using three antibiotic assembly and inserted at the EcoRI and PstI sites of the plasmid derived from pSTV28, whose construction has been previously described [32, 33, 34]. This plasmid was named pSTVPCB. In this plasmid, hol and $p c y A$ were constitutively transcribed independently following RBS in E. coli DH5 $\alpha$ by $\mathrm{P}_{\text {Ltete- } 1}$ polycistronically (Fig. 1). The components of this plasmid are shown in Table 1. 


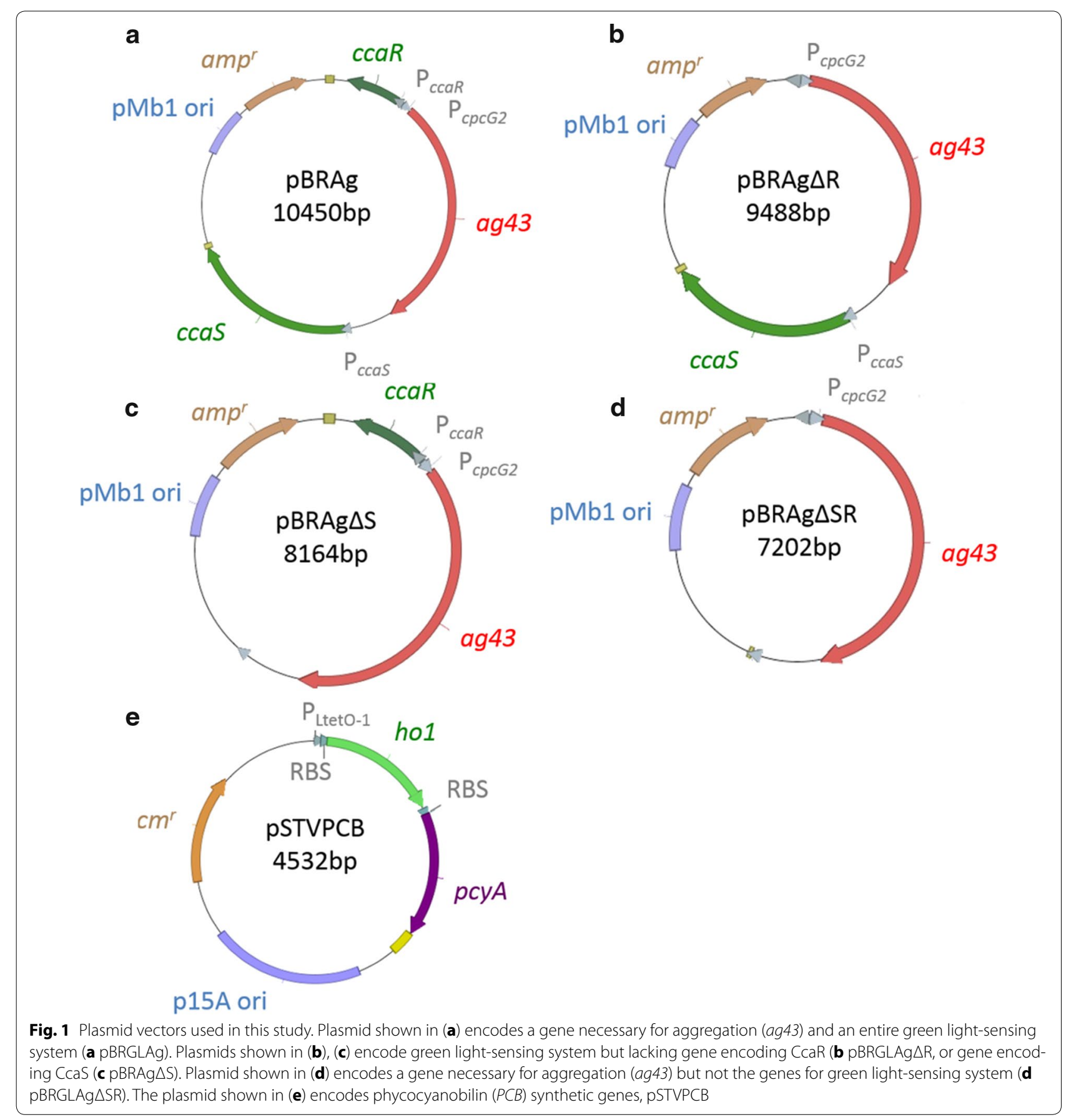

\section{Autoaggregation-regulation assay}

E. coli cells carrying pBRGLAg, pBRGLAg $\Delta$ S, pBRGLAg $\Delta \mathrm{R}$, or pBRGLAg $\triangle \mathrm{SR}$ together with $\mathrm{pSTVPCB}$ were cultured in LB broth containing $25 \mu \mathrm{g} / \mathrm{ml}$ chloramphenicol and $100 \mu \mathrm{g} / \mathrm{ml}$ ampicillin in a test tube at $37{ }^{\circ} \mathrm{C}$ with shaking at $140 \mathrm{rpm}$ overnight. The prepared pre-cultures were inoculated into fresh $40 \mathrm{ml} \mathrm{LB}$ broth containing 0.1 M HEPES (pH 6.6), $0.05 \mathrm{mM}$ aminolevulinic acid,
$0.05 \mathrm{mM} \mathrm{FeCl}, 100 \mu \mathrm{g} / \mathrm{ml}$ ampicillin, and $25 \mu \mathrm{g} / \mathrm{ml}$ chloramphenicol in 100-ml Erlenmeyer flasks. Cell density was monitored $6 \mathrm{~h}$ after the start of culture. Cells were cultured with shaking at $100 \mathrm{rpm}$ and exposed to red light $\left(660 \mathrm{~nm}, 40 \mu \mathrm{mol} \mathrm{s}{ }^{-1} \mathrm{~m}^{2}\right)$ at $30{ }^{\circ} \mathrm{C}$ until the cell density reached $\mathrm{OD}_{595}$ or $\mathrm{OD}_{600}=0.4-0.6$. After this period, each transformant was cultured under either of the following two conditions: one culture in triplicate was exposed to 
Table 1 Vector used in this study

\begin{tabular}{|c|c|c|c|c|}
\hline Plasmid name & Origin & Resistance & Feature & Source \\
\hline pKTGSS & V ori, p15A ori & Streptomycin & cca cluster with gfpuv instead of $c p c G 2$ & Ref. [20] \\
\hline pBRGLAg & pMb1 ori & Ampicillin & cca cluster with ag43 instead of cpcG2 & This study \\
\hline $\mathrm{pBRGLAg} \triangle S$ & pMb1 ori & Ampicillin & cca cluster with ag43 instead of cpcG2 without ccas & This study \\
\hline $\mathrm{pBRGLAg} \triangle \mathrm{R}$ & pMb1 ori & Ampicillin & cca cluster with ag43 instead of $c p c G 2$ without $c c a R$ & This study \\
\hline $\mathrm{pBRGLAg} \triangle \mathrm{SR}$ & pMb1 ori & Ampicillin & cca cluster with ag43 instead of $c p c G 2$ without ccaS, ccaR & This study \\
\hline pBR322 & pMb1 ori & Ampicillin/tetracycline & original vector used for construction of pBRGLAg & Ref. [31] \\
\hline PSTVPCB & p15A ori & Chloramphenicol & hol and pcyA genes for PCB synthesis & This study \\
\hline pSTV28 & p15A ori & Chloramphenicol & original vector used for construction of pSTV28 & Ref. [33] \\
\hline
\end{tabular}

green light ( $520 \mathrm{~nm}, 40 \mu \mathrm{mol} \mathrm{s}{ }^{-1} \mathrm{~m}^{2}$ ) instead of red light for $6 \mathrm{~h}$, and the other culture in triplicate was continuously exposed to red light with shaking at $100 \mathrm{rpm}$ and $30{ }^{\circ} \mathrm{C}$. A $10-\mathrm{ml}$ culture was transferred to a $15-\mathrm{ml}$ tube to measure the aggregation-regulation ability of the cells.

The transferred culture in each 15-ml tube was exposed to red light for $2 \mathrm{~h}$. During the incubation, a 100- $\mu \mathrm{l} \mathrm{cul-}$ ture was periodically transferred from the tube to a 96-well plate every $10 \mathrm{~min}$, and $200 \mu \mathrm{l}$ of fresh culture was added to the wells to dilute the culture. Cell density was measured using a plate reader (Thermo Fisher Scientific Inc., MA, USA). Cell density measurements were performed in triplicate. In all aggregation experiments, $E$. coli DH5 $\alpha$ was used.

\section{Transcriptional analysis of ag43 by quantitative reverse transcription PCR}

E. coli cells harboring PSTVPCB and pBRGLAg were cultured as described above in the aggregation-regulation assay. During culture, a 1-ml culture was periodically removed.

Total RNA was extracted from the cell pellets from 1-ml cultures taken after centrifugation at 12,000 g for 5 min at $4{ }^{\circ} \mathrm{C}$, using a NucleoSpin ${ }^{\circledR}$ RNA Clean-up kit (Takara Bio Inc., Shiga, Japan). The extracted RNA was treated with DNase to eliminate genomic DNA, and reverse transcription from RNA to CDNA was performed using PrimeScript ${ }^{\circledR}$ RT reagent kit with gDNA Eraser (Takara Bio Inc.). Quantitative PCR was performed to measure the transcriptional level of ag43 and $16 \mathrm{~S}$ ribosomal RNA (rRNA) (housekeeping genes) with $\mathrm{SYBR}^{\circledR}$ Premix Ex TaqTM II (Tli RNaseH Plus) (Takara Bio Inc.). The transcription level was measured using the $\Delta \Delta \mathrm{Ct}$ method and normalized using the calculated transcription values of $16 \mathrm{~S}$ rRNA.

\section{Evaluation of cell recovery}

Cells harboring the green light-inducible aggregation system were cultured as described above with modification in the timing of the start of exposure to green light.
To determine the timing of gene induction, cultures were induced by green light at different stages of growth. Four separate cultures in triplicate were prepared. For each culture, green light was irradiated at $\mathrm{OD}_{595}=0.7$, 1.1 , or 1.2 or until $10 \mathrm{~h}$ had passed after the cell density reached $\mathrm{OD}_{595}=1.7$. Cultures were then exposed to green light $\left(520 \mathrm{~nm}, 40 \mu \mathrm{mol} \mathrm{s}{ }^{-1} \mathrm{~m}^{2}\right)$ for $2 \mathrm{~h}$.

Cultures diluted to cell density $\mathrm{OD}_{595}=1.0$ by the addition of fresh LB broth containing 0.1 M HEPES (pH 6.6), $0.05 \mathrm{mM}$ aminolevulinic acid, $0.05 \mathrm{mM} \mathrm{FeCl}_{3}$, $100 \mu \mathrm{g} / \mathrm{ml}$ ampicillin, and $25 \mu \mathrm{g} / \mathrm{ml}$ chloramphenicol were transferred to a 15-ml tube and exposed to red light for $180 \mathrm{~min}$ for cell precipitation. Then, $7.6 \mathrm{ml}$ of the supernatant was sampled and $400 \mu \mathrm{l}$ of the culture containing precipitated cells was left behind (decantation procedure). The remained cells in $400 \mu \mathrm{l}$ of the culture was defined as the recovered cells. In order to quantify the amount of recovered cells and unrecovered cells, thus prepared $400 \mu \mathrm{l}$ of the culture containing precipitated cells and $7.6 \mathrm{ml}$ supernatant were centrifuged. The cell recovery was calculated as the ratio (\%) of the wet weight cells of recovered cells and total (recovered and unrecovered) cells.

\section{Results}

\section{Light-regulated precipitation}

E. coli transformants were grown under red light (660 nm, $40 \mu \mathrm{mol} \mathrm{m}^{-2} \mathrm{~s}^{-1}$ ) until the cell density reached the exponential growth phase $\left(\mathrm{OD}_{595}\right.$ or $\mathrm{OD}_{600}=0.5-$ 0.6). Red light exposure was then ceased, and the culture was continued under green light exposure. After $6 \mathrm{~h}$ of green light exposure, the precipitation of the cells was measured. Figure $2 \mathrm{a}-\mathrm{d}$ show the time courses of cell precipitation, including those harboring pSTVPCB for PCB synthesis and pBRGLAg encoding CcaS/CcaR and Ag43 under $\mathrm{P}_{c p c G 2}(2 \mathrm{a})$, pSTVPCB and pBRGLAg $\Delta \mathrm{S}$ (without $\mathrm{CcaS}$ ) (2b), pSTVPCB and pBRGLAg $\triangle \mathrm{R}$ (without CcaR) (2c), or pSTVPCB and pBRGLAg $\triangle S R$ (without CcaS/CcaR) (2d). The transformants harboring pSTVPCB and pBRGLAg exposed to green light $(520 \mathrm{~nm}$, 

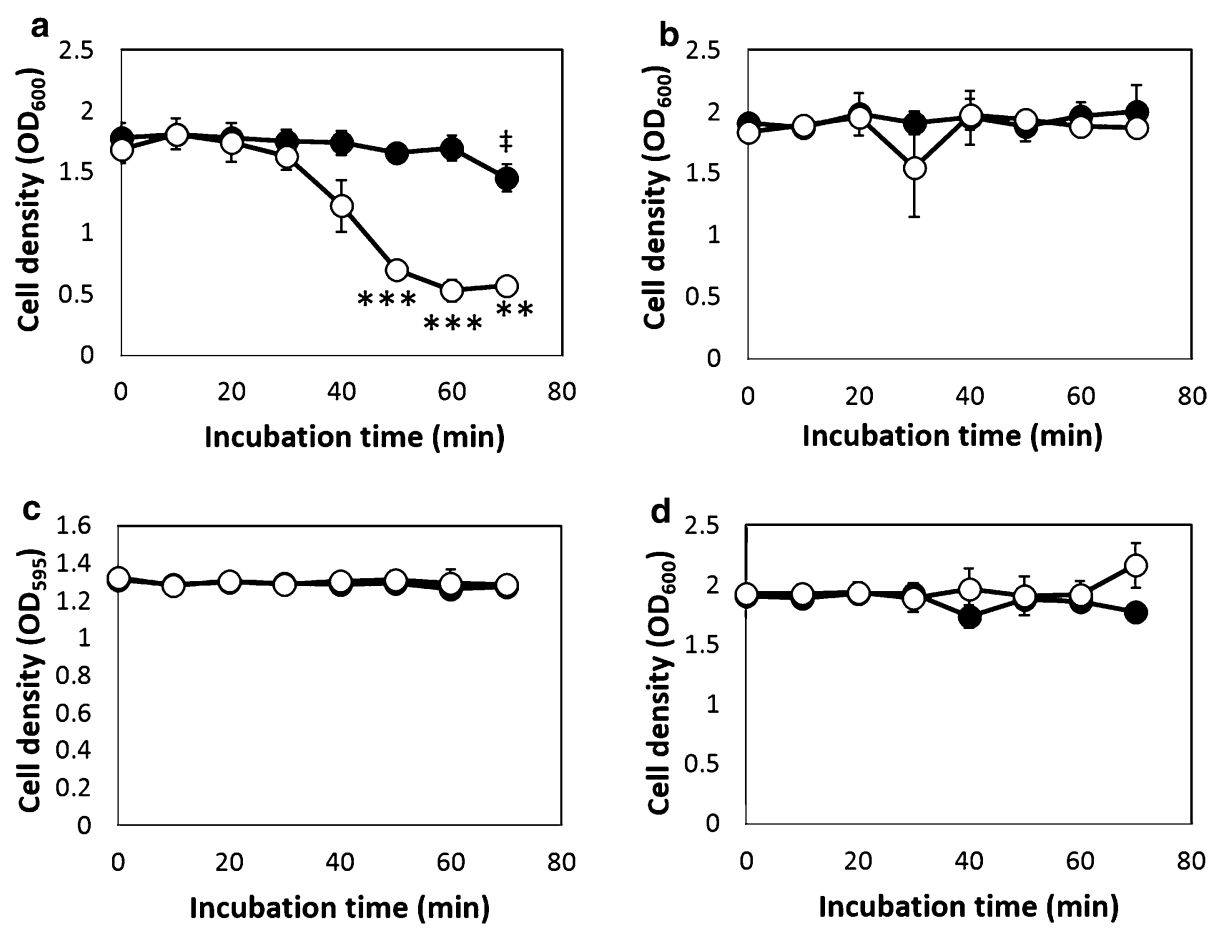

Fig. 2 Time course of aggregation of cells harboring a green light-inducible aggregation system. White circles show the time course of aggregation of cells grown under green light and black circles show the time course of aggregation of cells grown under red light. $\mathrm{OD}_{600}$ or $\mathrm{OD}_{595}$ were used as cell density indicators. a Cells harboring a green light-inducible aggregation system; b cells harboring a green light-inducible aggregation system lacking CcaS, the green light-sensor protein; c cells harboring a green light-inducible aggregation system lacking CcaR, the cognate response regulator of $\mathrm{CcaS}$; $\mathbf{d}$ cells harboring a green light-inducible aggregation system lacking $\mathrm{CcaS}$ and CcaR. The experiment was performed in triplicate. The double dagger indicates statistical difference in the cell density under red light from 0 min incubation $(\neq \mathrm{P}<0.05)$. The asterisks indicate statistical differences from the cells exposed to red light ${ }^{* *} \mathrm{P}<0.01$ and ${ }^{* *} \mathrm{P}<0.001$ based on Dunnet's t test)

$40 \mu \mathrm{mol} \mathrm{m} \mathrm{m}^{-2} \mathrm{~s}^{-1}$ ) started to decrease in $\mathrm{OD}_{600}$ during incubation, indicating that cell precipitation had started. After $60 \mathrm{~min}$ of incubation, the decrease in $\mathrm{OD}_{600}$ ceased at approximately $\mathrm{OD}_{600}=0.5$, indicating that cell precipitation had stopped. At this point, >50\% of the cells had precipitated. However, no precipitation was observed for transformants harboring PSTVPCB and pBRGLAg, which were exposed only to red light prior to the precipitation assay. In contrast, transformants harboring pSTVPCB and pBRGLAg $\triangle \mathrm{S}$, pBRGLAg $\triangle \mathrm{R}$, or pBRGLAg $\triangle S R$, cultured under red or green light, showed no decrease in $\mathrm{OD}_{595}$ or $\mathrm{OD}_{600}$, suggesting that these transformants had no precipitation ability (Fig. 2b, c, d). These results indicated that cell precipitation ability was induced when the transformants harbored both genes, those for PCB synthesis and for the complete two-component regulatory system $\mathrm{CcaS} / \mathrm{CcaR}$, and only when cultured under green light.

Transcriptional analysis of ag43 in transformants harboring pSTVPCB and pBRGLAg was performed. The transformants were cultured under red light for $12 \mathrm{~h}$ and then cultured under green light for the next $2 \mathrm{~h}$, whereas the other transformants were cultured under red light for $14 \mathrm{~h}$. Transcriptional analysis was performed for cells cultured after the first $12 \mathrm{~h}$ of culture (Fig. 3). The transcriptional level of ag43 gradually increased after exposure to green light for $20 \mathrm{~min}$. The transcriptional level reached to the highest level by $80 \mathrm{~min}$ incubation and remained stable for at least the next $20 \mathrm{~min}$ at least. Although an increase tendency of ag43 transcription was observed when the culture was exposed to red light, the transcriptional level was $<30 \%$ of that observed $80-110$ min after exposure to green light.

The results of the aggregation assays and transcriptional analysis indicated that the green light regulated aggregation of $E$. coli cells was achieved by introducing a green light-sensing two-component regulatory system derived from cyanobacteria and Ag43 gene.

\section{Cell recovery}

The engineered $E$. coli cells harboring PSTVPCB and pBRGLAg were then subjected to investigation of cell recovery. Cells were cultured under green or red light (Fig. 4). After an approximately 12-h lag phase, 


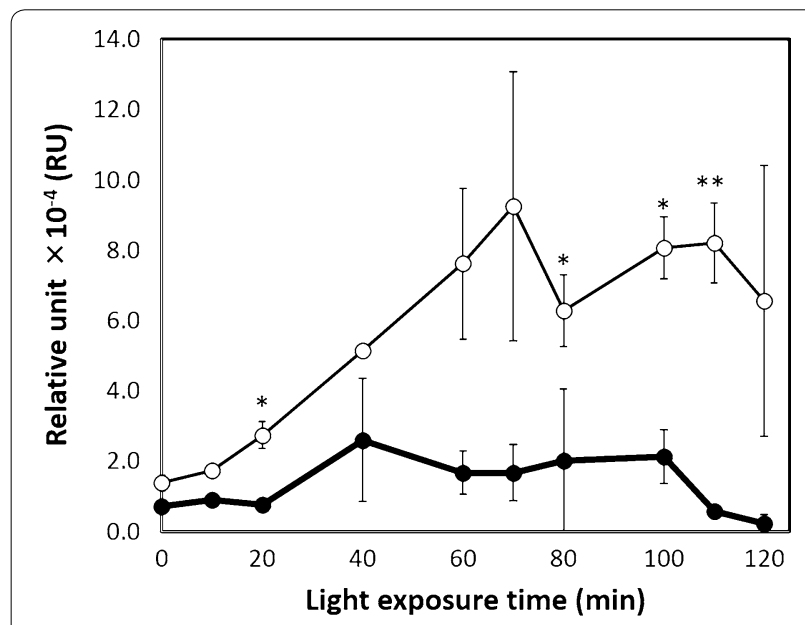

Fig. 3 Transcriptional analyses of Ag43 under green light induction. Relative units of ag43 transcription were normalized to 16S rRNA amounts. Relative units in cells grown under green light are shown with white circles, and relative units in cells grown under red light are shown with black circles. There is no significant difference in the cell density under red light at each incubation time from at 0 min incubation. The asterisks indicate statistical difference from the cells exposed to red light ( ${ }^{*} P<0.05$ and ${ }^{* *} P<0.01$, based on Dunnet's t-test)

cell growth entered the logarithmic growth phase and reached the stationary phase after $30 \mathrm{~h}$. Cells at each growth phase, the early logarithmic growth phase (12-18 h; $\mathrm{OD}_{595}=$ approximately 0.7$)$, mid-logarithmic growth phase (18-28 h; $\mathrm{OD}_{595}=$ approximately 1.0), late logarithmic growth phase $\left(28-32 \mathrm{~h}\right.$; $\mathrm{OD}_{595}=$ approximately 1.8$)$, and stationary phase (10 h after the late log phase), were exposed to green light to induce precipitation. Cultures containing cells exposed to green light at each growth phase were diluted to $\mathrm{OD}_{595}=1.0$ by addition of LB broth, and an $8 \mathrm{ml}$ culture of each was transferred to a $15-\mathrm{ml}$ tube. Tubes were exposed to red light.

Cells at all growth phases showed precipitation ability, with 2-h exposure to green light resulting in Ag43 expression. Amounts of cells recovered by decantation of the precipitated cells are shown in Fig. 4. From the cells exposed to green light at the early, middle, and late-logarithmic growth phases, $>70 \%$ of cells were recovered by decantation. However, for cells exposed to green light at the stationary phase, $<50 \%$ of total number of cells was recovered by decantation. Thus, for efficient recovery of engineered $E$. coli cells harboring pSTVPCB and pBRGLAg, cells should be exposed to green light before growth enters the stationary phase, preferably before the late logarithmic phase. These results demonstrate the construction of a green light-induced cell recovery system for non-photosynthetic microorganisms by the combination of a cyanobacteria-derived green light-sensing system and Ag43 from E. coli.

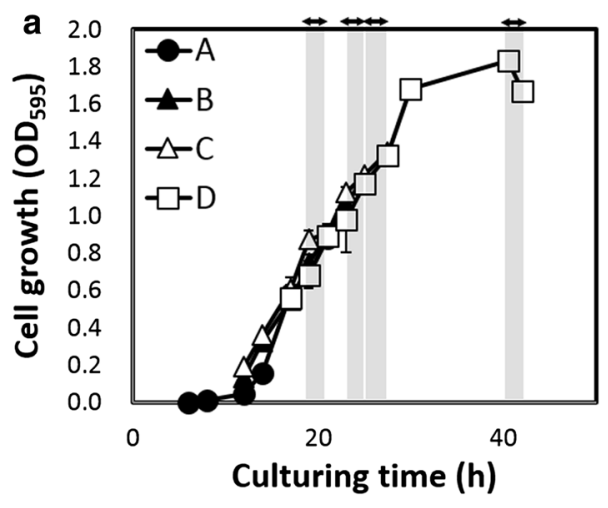

b

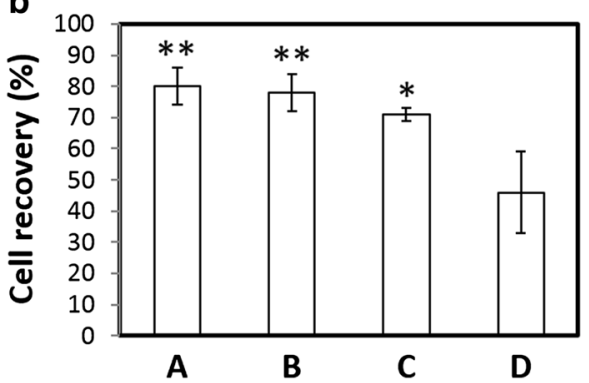

Fig. 4 Evaluation of cell recovery under green light induction at various cell growth phases. a Time course of cell growth. $\mathbf{b}$ Cell recovery from cultures exposed to green light for $2 \mathrm{~h}$. Cell recovery is shown as the ratio (\%) of recovered cells (wet weight) to total cells (wet weight) in culture in a tube. The asterisks indicate statistical differences from the cells exposed to green light on stationary phase ${ }^{*} \mathrm{P}<0.05$ and ${ }^{* *} \mathrm{P}<0.01$ based on Dunnet's t-test). A Cells exposed to green light at 19-21 h of culture, early log phase; $B$ cells exposed to green light at 23-25 h of culture, middle log phase. C Cells exposed to green light at 25-27 h of culture, late log phase; D cells exposed to green light at $40-42 \mathrm{~h}$ of culture, stationary phase

\section{Discussion}

In this study, we aimed to construct a green light-regulated cell recovery system for non-photosynthetic microorganisms using a green light-regulated gene expression system controlled by a two-component regulatory system from cyanobacteria and using Ag43, an autotransporter protein from E. coli.

Recently, the crystal structure of $\alpha$-domain of Ag43 has been reported [29]. The crystal structure of this domain shows that the formation of cell aggregates proceeds via a molecular Velcro-like handshake mechanism. Under this mechanism, if Ag43 is expressed on the surface of the outer membrane, cell self-aggregation will occur. The self-aggregation of bacteria using recombinant Ag43 has been previously reported [28]. Exogenously introduced Ag43 led to the self-aggregation of E. coli, Pseudomonas fluorescens, and Klebsiella pneumoniae. Thus, our green light-induced cell recovery system will also be useful in a variety of non-photosynthetic microorganisms if the functional expression of the green light-sensing system is 
possible with the introduction of the PCB synthesis gene cassette.

Cell precipitation was observed in green light-exposed transformants harboring both PSTVPCB for PCB synthesis and pBRGLAg encoding CcaS/CcaR and Ag43 under $\mathrm{P}_{c p c G 2}$ but not in transformants harboring pSTVPCB and with an imperfect green light-regulation system (pBRGLAg $\Delta$ S, pBRGLAg $\Delta$ R, or pBRGLAg $\Delta$ SR) (Fig. 2ad). However, even in the transformants with pSTVPCB and pBRGLAg, slight precipitation was observed under red light exposure at $70 \mathrm{~min}$ of incubation (Fig. 2a). Although the slight precipitation of the cells exposed to red light was observed at $70 \mathrm{~min}$ incubation, the expression of Ag43 under red light was not observed by transcriptional analysis (Figs. 2, 3). However, because the increase tendency was observed in the ag43 transcription under red light, the result suggests undetectable level ag43 transcription under red light led to Ag43 expression and precipitation of cells under red light. The difference in the Ag43 expression levels of transformants with pSTVPCB and pBRGLAg under red light was obvious in transformants harboring an imperfect green lightsensing system with ag43. Thus, the expression of Ag43 under red light was not due to the endogenously present $\mathrm{P}_{c p c G 2}$ activating factors in E. coli but due to backgroundlevel expression under red light in the presence of CcaS/ $\mathrm{CcaR}$. It has been reported that $\mathrm{CcaS}$ autophosphorylation was repressed under red light. To prevent expression leakage of Ag43 under non-inducing conditions, we cultured E. coli transformants under red light. However, further repression of kinase activity of $\mathrm{CcaS}$ is required to achieve tight regulation using this system.

Cell recovery by exposure to green light was achieved when the cells were induced before entry into the stationary phase. However, when cells were exposed to green light even at the early-logarithmic growth phase, $80 \%$ could be recovered by decantation with $20 \%$ remaining in the culture supernatant. Aggregation is strongly dependent on the cell concentration [27]. With decreasing free cell concentration in the supernatant resulting from the precipitation of flocculate from Ag43-mediated aggregation, aggregation may decrease. To overcome this inherent problem of aggregation-mediated cell recovery, an increase in the expression level of Ag43 per cell would enhance cell precipitation.

\section{Conclusions}

In conclusion, this study demonstrated the construction of a cell recovery system for non-photosynthetic microorganisms that is induced by the exposure of cells to green light. The system is regulated by a two-component regulatory system from cyanobacteria, and the cell precipitation is mediated by an autotransporter protein,
Ag43. Although further strict control and increase of cell recovery efficiency are necessary, the proposed system provides a novel tool for future bioprocessing with reduced energy and labor for cell recovery.

\section{Authors' contributions}

MN; Mitsuharu Nakajima, KA; Koichi Abe, SF; Stefano Ferri, KS; Koji Sode MN conducted the preparation of recombinant cells and experiments throughout this research. KA designed the genes and vectors used in this research. SF and KS designed the plan of this research and performed the data analysis. KS has supervised this study. All authors participated in design and coordination and wrote the manuscript. All authors read and approved the final manuscript.

\section{Author details}

${ }^{1}$ Department of Biotechnology and Life Science, Graduate School of Engineering, Tokyo University of Agriculture \& Technology, 2-24-16 Naka-cho, Koganei, Tokyo 184-8588, Japan. ${ }^{2}$ Japan Science and Technology Agency, CREST, 2-24-16 Naka-cho, Koganei, Tokyo 184-8588, Japan. ${ }^{3}$ Department of Applied Chemistry and Biochemical Engineering, Shizuoka University, 3-5-1 Johoku, Naka-ku, Hamamatsu, Shizuoka 432-8561, Japan.

\section{Acknowledgements}

Financial support was obtained through the Core Research of Evolutional Science \& Technology (CREST) program from the Japan Science and Technology Agency (JST).

\section{Competing interests}

The authors declare that they have no competing interests.

Received: 1 November 2015 Accepted: 19 January 2016

Published online: 15 February 2016

\section{References}

1. Levskaya A, Weiner OD, Lim WA, Voigt CA. Spatiotemporal control of cell signalling using a light-switchable protein interaction. Nature. 2009;461:997-1001.

2. Wu YI, Frey D, Lungu OI, Jaehrig A, Schlichting I, Kuhlman B, et al. A genetically encoded photoactivatable Rac controls the motility of living cells. Nature. 2009;461:104-10.

3. Masuda S, Nakatani Y, Ren S, Tanaka M. Blue light-mediated manipulation of transcription factor activity in vivo. ACS Chem Biol. 2013;8:2649-53.

4. Schierling B, Pingoud A. Controlling the DNA cleavage activity of lightinducible chimeric endonucleases by bidirectional photoactivation. Bioconjugate Chem. 2012;23:1105-9.

5. Ohlendorf R, Vidavski RR, Eldar A, Moffat K, Möglich A. From dusk till dawn: one-plasmid systems for light-regulated gene expression. J Mol Biol. 2012;416:534-42.

6. Wang $X$, Chen $X$, Yang Y. Spatiotemporal control of gene expression by a light-switchable transgene system. Nat Methods. 2012;9:266-9.

7. van Bergeijk P, Adrian M, Hoogenraad CC, Kapitein LC. Optogenetic control of organelle transport and positioning. Nature. 2015;518:111-4.

8. Liu X, Ramirez S, Pang PT, Puryear CB, Govindarajan A, Deisseroth K, et al. Optogenetic stimulation of a hippocampal engram activates fear memory recall. Nature. 2012;484:381-5.

9. Terauchi K, Montgomery BL, Grossman AR, Lagarias JC, Kehoe DM. RcaE is a complementary chromatic adaptation photoreceptor required for green and red light responsiveness. Mol Microbiol. 2004;51:567-77.

10. Hirose Y, Narikawa R, Katayama M, Ikeuchi M. Cyanobacteriochrome CcaS regulates phycoerythrin accumulation in nostoc punctiforme, a group II chromatic adapter. Proc Natl Acad Sci USA. 2010;107:8854-9.

11. Bonetti C, Stierl M, Mathes T, van Stokkum IH, Mullen KM, Cohen-Stuart TA, et al. The role of key amino acids in the photoactivation pathway of the Synechocystis SIr1694 BLUF domain. Biochemistry. 2009;48:11458-69.

12. Cao Z, Livoti E, Losi A, Gärtner W. A blue light-inducible phosphodiesterase activity in the cyanobacterium Synechococcus elongatus. Photochem Photobiol. 2010;86:606-11. 
13. Enomoto G, Nomura R, Shimada T, Win NN, Narikawa R, Ikeuchi M. Cyanobacteriochrome SesA is a diguanylate cyclase that induces cell aggregation in Thermosynechococcus. J Biol Chem. 2014;289:24801-9.

14. Enomoto G, Win NN, Narikawa R, Ikeuchi M. Three cyanobacteriochromes work together to form a light color-sensitive input system for c-di-GMP signaling of cell aggregation. PNAS. 2015;112:8082-7.

15. Yoshihara S, Shimada T, Matsuoka D, Zikihara K, Kohchi T, Tokutomi S. Reconstitution of blue-green reversible photoconversion of a cyanobacterial photoreceptor, PixJ1, in phycocyanobilin-producing Escherichia coli. Biochemistry. 2006;45:3775-84.

16. Narikawa R, Suzuki F, Yoshihara S, Higashi S, Watanabe M, Ikeuchi M. Novel photosensory two-component system (PixA-NixB-NixC) involved in the regulation of positive and negative phototaxis of cyanobacterium Synechocystis sp. PCC 6803. Plant Cell Physiol. 2011;52:2214-24.

17. Songa JY, Chob HS, Choc JI, Jeonc JS, Lagariasd JC, Parka YI. Near-UV cyanobacteriochrome signaling system elicits negative phototaxis in the cyanobacterium Synechocystis sp. PCC 6803. PNAS. 2011;108:10780-5.

18. Hirose Y, Shimada T, Narikawa R, Katayama M, Ikeuchi M. Cyanobacteriochrome CcaS is the green light receptor that induces the expression of phycobilisome linker protein. PNAS. 2008;105:9528-33.

19. Abe K, Miyake K, Nakamura M, Kojima K, Ferri S, Ikebukuro K, et al. Engineering of a green-light inducible gene expression system in Synechocystis sp. PCC6803. Microb Biotechnol. 2014;7:177-83.

20. Badary A, Abe K, Ferri S, Kojima K, Sode K. The development and characterization of an exogenous green-light-regulated gene expression system in marine cyanobacteria. Mar Biotechnol. 2015;17:245-51.

21. Miyake K, Abe K, Ferri S, Nakajima M, Nakamura M, Yoshida W. A greenlight inducible lytic system for cyanobacterial cells. Biotechnol Biofuels. 2014;7:56.

22. Tabor JJ, Levskaya A, Voigt CA. Multichromatic control of gene expression in Escherichia coli. J Mol Biol. 2011;405:315-24.

23. Gambetta GA, Lagarias JC. Genetic engineering of phytochrome biosynthesis in bacteria. PNAS. 2001;98:10566-71.

24. Diderichsen B. Flu, a metastable gene controlling surface properties of Escherichia coli. J Bacteriol. 1980;141:858-67.

25. Owen P, Meehan M, de Loughry-Doherty $H$, Henderson I. Phase-variable outer membrane proteins in Escherichia coli. FEMS Immunol Med Microbiol. 1996;16:63-76.
26. Henderson IR, Meehan M, Owen P. Antigen 43, a phase-variable bipartite outer membrane protein, determines colony morphology and auto-aggregation in Escherichia coli K-12. FEMS Microbiol Lett. 1997;149:115-20.

27. Hasman H, Chakraborty T, Klemm P. Antigen-43-mediated autoaggregation of Escherichia coli is blocked by fimbriation. J Bacteriol. 1999;181:4834-41.

28. Kjærgaard K, Schembri MA, Hasman H, Klemm P. Antigen 43 from Escherichia coli induces inter- and intraspecies cell aggregation and changes in colony morphology of pseudomonas fluorescens. J Bacteriol. 2000;182:4789-96.

29. Heras B, Totsika M, Peters KM, Paxman JJ, Gee CL, Jarrott RJ, et al. The antigen 43 structure reveals a molecular Velcro-like mechanism of autotransporter-mediated bacterial clumping. PNAS. 2014;111:457-62.

30. Registry of Standard Biological Parts. http://www.partsregistry.org.

31. Bolivar F, Rodriguez RL, Greene PJ, Betlach MC, Heyneker HL, Boyer HW, et al. Construction and characterization of new cloning vehicles. II. A multipurpose cloning system. Gene. 1977;2:95-113.

32. Shetty R, Lizarazo M, Rettberg R, Knight TF. Assembly of BioBrick standard biological parts using three antibiotic assembly. In: Voigt C, editor. Methods Enzymol. London: Academic; 2011. p. 311-326.

33. Chang ACY, Cohen SN. Construction and characterization of amplifiable multicopy DNA cloning vehicles derived from the P15A cryptic miniplasmid. J Bacteriol 1978;134:1141-1156.

34. Sakai Y, Abe K, Nakashima S, Yoshida W, Ferri S, Sode K, et al.: Improving the gene-regulation ability of small RNAs by scaffold engineering in Escherichia coli. ACS Synth Biol 2014;3:152-162.

\section{Submit your next manuscript to BioMed Central and we will help you at every step:}

- We accept pre-submission inquiries

- Our selector tool helps you to find the most relevant journal

- We provide round the clock customer support

- Convenient online submission

- Thorough peer review

- Inclusion in PubMed and all major indexing services

- Maximum visibility for your research

Submit your manuscript at www.biomedcentral.com/submit

\section{(O) Biomed Central}

